J. Dairy Sci. 104:1424-1432

https://doi.org/10.3168/jds.2020-19071

(C) 2021, The Authors. Published by Elsevier Inc. and Fass Inc. on behalf of the American Dairy Science Association ${ }^{\circledR}$.

This is an open access article under the CC BY-NC-ND license (http://creativecommons.org/licenses/by-nc-nd/4.0/).

\title{
Effects of seasonal variations on the quality of set yogurt, stirred yogurt, and Greek-style yogurt
}

\section{Siqi Li, $\odot$ Aiqian Ye, ${ }^{*} \odot$ and Harjinder Singh $\odot$}

Riddet Institute, Massey University, Private Bag 11 222, Palmerston North 4442, New Zealand

\begin{abstract}
We studied the effects of seasonal variations on the quality of stirred yogurt, set yogurt, and Greek-style yogurt over 2 milking seasons in New Zealand. Correlations between the properties of the yogurts, the characteristics of the milk, and the acid gelation properties induced by glucono- $\delta$-lactone, reported in our previous works, were also explored. Set yogurt and Greek-style yogurt from the early season had the highest firmness over the seasons. The yogurt firmness correlated with the gel strength of glucono- $\delta$-lactone-induced acid gels, indicating that the latter could, to some extent, predict the seasonal variations in the firmness of set yogurt. The correlation studies highlighted the potentially important role of the glycosylation of $\kappa$-casein in the seasonal variations in the yogurt structures. Yogurt made from mid-season milk had the lowest water-holding capacity, which may have played a part in lowering its firmness and viscosity. Late-season stirred yogurt displayed the strongest resistance to shear-induced thinning, which might arise from the unique viscoelastic properties of late-season yogurt gels.
\end{abstract}

Key words: yogurt, Greek-style yogurt, seasonal variation, acid milk gel, texture analysis

\section{INTRODUCTION}

Yogurt is a popular dairy product around the world, not only for its unique texture and flavor but also for its health benefits (Macori and Cotter, 2018). The manufacture of yogurt involves the acid gelation of milk, which is induced by the fermentation of lactose to lactic acid by lactic acid bacteria. Different types of yogurt are manufactured by varying the processing conditions and the composition of the milk base. Set yogurt is incubated in retail containers, keeping the gel structure undisturbed. Stirred yogurt is incubated in large fermentation vessels and is stirred to obtain a smooth and

Received June 11, 2020.

Accepted September 19, 2020.

*Corresponding author: a.m.ye@massey.ac.nz viscous product before filling and packaging. In recent years, Greek-style yogurt (GSY) has grown in popularity and market share (Desai et al., 2013; Bong and Moraru, 2014; Dharmasena et al., 2014). Traditionally, GSY is produced by straining yogurt to attain the desired level of total solids (Nsabimana et al., 2005). In the modern manufacturing process of GSY, the milk base is concentrated by UF or the addition of milk solids (wet or dry) before fermentation, which avoids the generation of acid whey (Uduwerella et al., 2017; Jørgensen et al., 2019).

Seasonality plays a role in altering the composition and physicochemical properties of bovine milk and subsequently affects the quality of dairy products. The effects of seasonal variation are particularly pronounced in seasonal-calving countries such as New Zealand, where most dairy cows calve at the same period of the year (Auldist et al., 1998; Li et al., 2019). A better understanding of the effects of seasonality on the properties of yogurt would allow better control of the product quality and would assist in the development of new types of fermented dairy products to meet ever-changing consumer preferences. Very limited information has been published on the seasonal variations in yogurt properties. Cheng et al. (2002) studied the properties of yogurts made from reconstituted concentrated skim milk produced at different times of the year in Australia. They reported seasonal variations in the firmness of set yogurt, the viscosity of stirred yogurt, and the extent of syneresis. However, no clear trend during the year was reported.

Our previous work investigated the seasonal variations in the acid gelation properties of milk, as induced by glucono- $\delta$-lactone (GDL; Li et al., 2020). We found that acid gels made from late-season milk had the lowest gelation $\mathrm{pH}$, the longest gelation time, and the lowest elastic modulus $\left(\mathbf{G}^{\prime}\right)$. The effects of some important processing parameters, such as heating, on yogurt have been demonstrated in acid gelation studies using GDL (Lucey and Singh, 1997; Lucey et al., 1997; Guyomarc'h et al., 2003). However, Lucey et al. (1998) suggested that the conclusions drawn from GDL-induced acid gelation studies should be validated in yogurt systems 
made by bacterial fermentation because of the differences in the acidification rates and the structures of the resulting gels.

The objective of this study was to investigate and understand the seasonal variations in the properties of yogurts. Raw milk for yogurt making was sampled for 2 full milking seasons from a typical New Zealand herd to determine the robustness of the seasonal variation patterns. To provide information on different product systems, we studied 3 types of yogurt: set yogurt, stirred yogurt, and GSY. The firmness of set yogurt and GSY and the viscosity of stirred yogurt were determined. In particular, the analysis of firmness was performed on both fresh samples and stored samples to account for reported changes during the yogurt's shelf life (Sodini et al., 2004). In addition, the syneresis and the waterholding capacity (WHC) of the yogurts were studied.

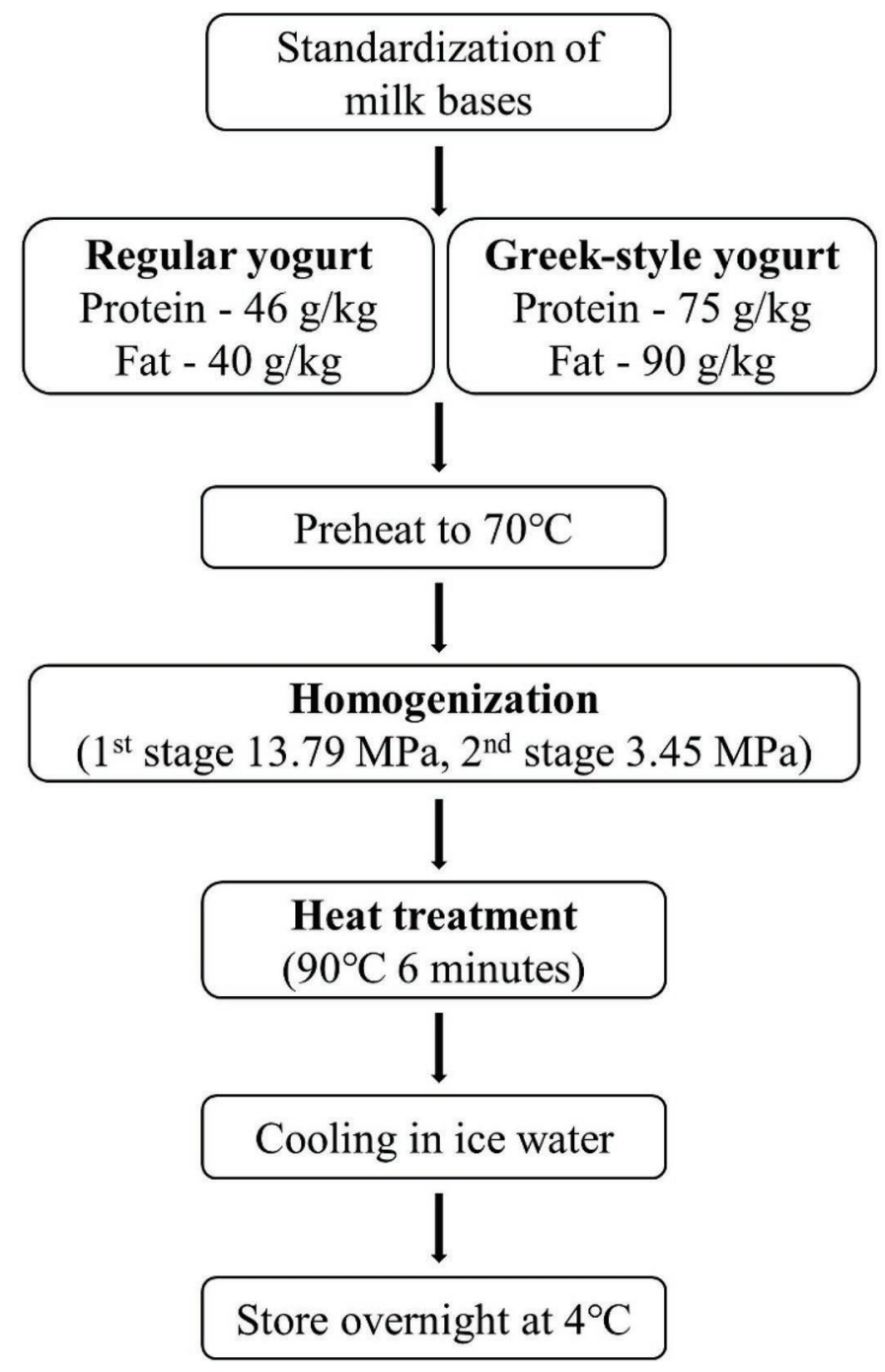

Figure 1. Flowchart of yogurt milk base preparation.
We analyzed and discussed the correlations between yogurt properties and seasonal milk characteristics reported in our previous work ( $\mathrm{Li}$ et al., 2019). The standardized milk base used for making regular set yogurt and stirred yogurt was also used in our work on GDL-induced acid gelation (Li et al., 2020). This allowed direct comparisons between GDL-induced acid gels and yogurts so that we could explore the usefulness of the GDL-induced acid gel as an indicator of the seasonal variations in yogurt properties.

\section{MATERIALS AND METHODS}

\section{Milk Sampling, Initial Processing, and Characterizations}

Raw milk was sampled from Massey University No. 4 Dairy Farm for 2 milking seasons in the years 2016 to 2017 and 2017 to 2018. Early season, mid-season, and late season were defined as corresponding to August to October, November to February, and March to May in each year. In each season of each year, 4 to 6 batches of yogurt were made and analyzed. Detailed information on the herd and the sampling is given in Li et al. (2019).

Pasteurized skim milk, cream, and UF retentate and permeate were obtained by the processing of raw milk, and their protein and fat contents were analyzed as described in Li et al. (2020). The protein composition (including the proportion of glycosylated $\kappa$-casein and non-glycosylated $\kappa$-casein), total calcium, ionic calcium, heat-induced whey protein denaturation, and whey protein-casein micelle association of seasonal milk were determined and reported in $\mathrm{Li}$ et al. (2019).

\section{Yogurt Milk Preparation and Fermentation}

The processing of the yogurt milk bases and the yogurt-making process are presented in Figure 1 and Figure 2. Regular yogurt milk base ( $46 \mathrm{~g} / \mathrm{kg}$ protein, 40 $\mathrm{g} / \mathrm{kg}$ fat) and GSY milk base $(75 \mathrm{~g} / \mathrm{kg}$ protein, $90 \mathrm{~g} / \mathrm{kg}$ fat) were standardized by mixing skim milk, cream, and UF retentate (or permeate) in calculated ratios. The milk bases were preheated to $70^{\circ} \mathrm{C}$ and homogenized in a 2-stage homogenizer under pressures of $13.79 \mathrm{MPa}$ in the first stage and $3.45 \mathrm{MPa}$ in the second stage. The homogenized yogurt milk base was heated at $90 \pm$ $0.5^{\circ} \mathrm{C}$ for $6 \mathrm{~min}$, chilled immediately in ice water, and stored at $4^{\circ} \mathrm{C}$ overnight before fermentation.

The yogurt milk bases were fermented using an exopolysaccharide-producing ABT-10 culture (Chr. Hansen, Hørsholm, Denmark), which consisted of Streptococcus thermophilus, Lactobacillus acidophilus, and Bifidobacterium bifidus. Before inoculation, the 


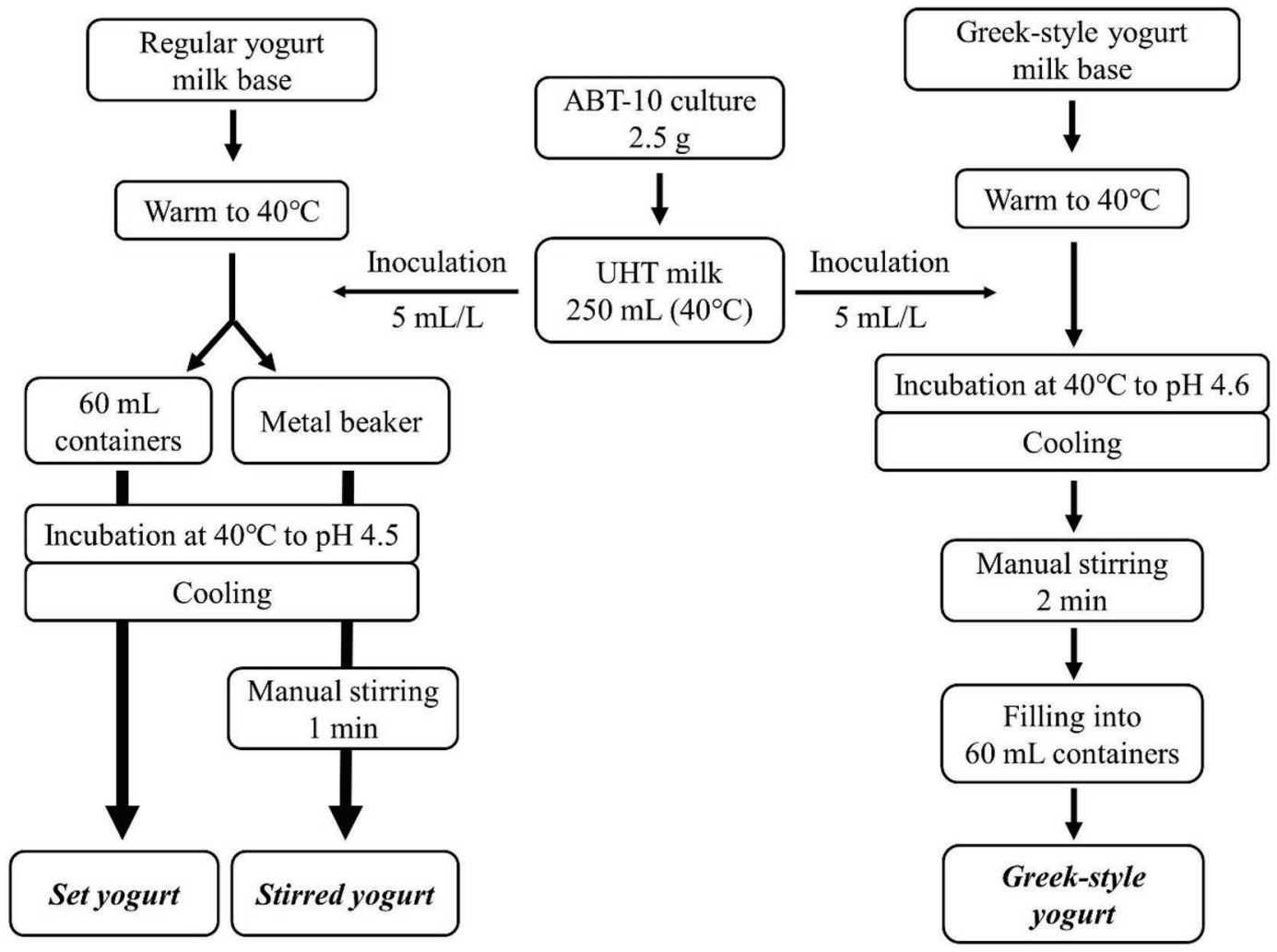

Figure 2. Flowchart of yogurt making.

milk bases were warmed to $40^{\circ} \mathrm{C}$ in a water bath. Then, $2.5 \mathrm{~g}$ of the culture was dissolved in $250 \mathrm{~mL}$ of commercial UHT milk and stirred for 2 min. This cultured milk was used to inoculate the yogurt milk bases at a dosage of $5 \mathrm{~mL} / \mathrm{L}$. Fermentation was carried out at $40^{\circ} \mathrm{C}$ in an incubator (Contherm Scientific, Lower Hutt, New Zealand).

The fermentation of regular yogurt was carried out in 3 types of container and was terminated when the $\mathrm{pH}$ reached 4.5. The first part of the inoculated milk was filled into cylinder-shaped $60-\mathrm{mL}$ containers $(43 \mathrm{~mm}$ in diameter) to the $50-\mathrm{mL}$ (35-mm height) mark and incubated. The set yogurt made in these containers was used to determine spontaneous syneresis and firmness. The second part of the inoculated milk (around $45 \mathrm{~g}$ ) was fermented in 50-mL centrifuge tubes, to be used to determine the WHC of the set yogurts. The rest of the inoculated milk was fermented in a cylindrical metal beaker (diameter $15.5 \mathrm{~cm}$, height $20.5 \mathrm{~cm}$ ). The yogurt was stirred manually in the beaker with a spatula (4.7 $\mathrm{cm} \times 5.5 \mathrm{~cm})$ in a circular motion for $1 \mathrm{~min}$. This stirring time had been determined in preliminary tests to give a visually smooth reference stirred yogurt. The fermentation of GSY was also performed in the 3 types of container, as previously described, and was termi- nated when the $\mathrm{pH}$ reached 4.6. The time to reach the termination $\mathrm{pH}$ was defined as the fermentation time, and it was determined for both the regular yogurt and the GSY. There were 2 differences in the fermentation processes for regular yogurt and GSY: (1) the GSY incubated in the $60-\mathrm{mL}$ containers was used only for the spontaneous syneresis test; (2) the GSY incubated in the metal beakers was stirred in the same way as described above but for 2 min. After stirring, the GSY was filled into the $60-\mathrm{mL}$ containers previously described, for texture analysis. All samples were stored at $4^{\circ} \mathrm{C}$ until further analysis.

\section{Texture Analysis of Set Yogurt}

The firmness of the set yogurt and the GSY in the 60-mL containers was determined using a back-extrusion method on a texture analyzer TA XT Plus (Stable Micro Systems, Godalming, Surrey, UK). A geometry with a round flat surface ( $40 \mathrm{~mm}$ in diameter) was used, allowing a space of $1.5 \mathrm{~mm}$ between the geometry and the sample container (43 $\mathrm{mm}$ in diameter). The analysis was performed by lowering the geometry at a speed of $1 \mathrm{~mm} / \mathrm{s}$ into the yogurt sample for $30 \mathrm{~s}$. Preliminary tests showed that the measured force increased during 
the first $5 \mathrm{~s}$ and then plateaued. The firmness $(\mathrm{N} \cdot \mathrm{s})$ of yogurt is defined as the area under the time-force curve from 5 to $30 \mathrm{~s}$. The firmness of set yogurt was measured after 1 and $7 \mathrm{~d}$ of storage, whereas that of GSY was determined after $1,7,14$, and $28 \mathrm{~d}$ of storage. The firmness results obtained after overnight storage and the mean firmness over the storage period were recorded. Each sample was measured in triplicate.

\section{Apparent Viscosity Measurement of Stirred Yogurt}

The apparent viscosity of stirred yogurt was determined on an AR-G2 Magnetic Bearing Rheometer (TA Instruments, Crawley, West Sussex, UK) in combination with a cone and plate geometry (steel cone of 40 mm diameter, $4^{\circ}$ cone). A constant shear rate of $50 \mathrm{~s}^{-1}$ was applied to simulate oral processing (Wood, 1968). Apparent viscosity readings (Pa.s) were taken every 10 $\mathrm{s}$ for $3 \mathrm{~min}$ at $4^{\circ} \mathrm{C}$. The initial viscosity $\left(\boldsymbol{\eta}_{\mathbf{0}}\right)$ and the median viscosity during the 3 min $\left(\boldsymbol{\eta}_{\text {median }}\right)$ were determined. The $\eta_{\text {median }} / \eta_{0}$ ratio was calculated to indicate the resistance of the structural integrity of the stirred yogurt to shearing.

\section{Spontaneous Syneresis and WHC}

The extent of spontaneous syneresis was determined as the weight percentage of free whey in the total yogurt weight immediately after fermentation. Spontaneous syneresis measurements were made in triplicate.

The WHC of yogurt was defined as the weight percentage of concentrated yogurt, after centrifugation at $1,000 \times g$ for $10 \mathrm{~min}$, in the original yogurt. About 45.0 $\mathrm{g}$ of yogurt was weighed and centrifuged in a $50-\mathrm{mL}$ centrifuge tube. Regular set yogurt and GSY were fermented in the centrifuge tubes, whereas stirred yogurt was filled into the tubes after stirring and overnight storage at $4^{\circ} \mathrm{C}$. The WHC tests were duplicated for each sample.

\section{Statistical Analysis}

We used IBM SPSS version 24 (IBM Corp., Armonk, NY) for statistical analysis. The overall effects of season, year, and their interactions on the yogurt properties were determined using 2-way ANOVA with the Tukey post hoc test. The effect of seasonal variation in each year was analyzed using 1-way ANOVA with the Tukey post hoc test, whereas the effect of between-year variation in each season was analyzed using independent sample $t$-tests. The coefficient of variation $(\mathrm{CV}$, the ratio between the standard deviation and the mean as a percentage) was determined, to indicate the extent of variation. Pearson correlation coefficients between the properties of the yogurts determined in the current study, the characteristics of the milk and heat-induced changes reported in $\mathrm{Li}$ et al. (2019), and the GDLinduced acid gelation properties reported in $\mathrm{Li}$ et al. (2020) were determined.

\section{RESULTS AND DISCUSSION}

\section{Fermentation Time of Regular Yogurt and GSY}

The fermentation time of regular yogurt was not affected by the season in either year, but the overall fermentation time was longer in 2016 to 2017 than in 2017 to 2018 (Table 1). The similar fermentation time during the different seasons was expected, as the process of standardization eliminated the variation in the buffering capacity of seasonal milks (Li et al., 2019). Cheng et al. (2002) also reported that the fermentation time of yogurt made from reconstituted milk was not affected by the season in which the milk powders were produced in Australia. The longer fermentation time in 2016 to 2017 may have been a result of the higher CN content of the milk (Li et al., 2019), which would result in a stronger buffering capacity. The longer fermentation time correlated moderately with the higher proportion of $\mathrm{CN}$ in the total milk proteins $(\mathrm{r}=0.384 ; P=0.04)$. Similar to the regular yogurt, the fermentation time of GSY also did not vary with the season. Milk from 2016 to 2017 also had a longer fermentation time than milk from 2017 to 2018, although the difference was not statistically significant $(P=0.054)$.

\section{Firmness of Set Yogurt and GSY}

Set Yogurt. No significant effect of storage for $7 \mathrm{~d}$ on the firmness of the set yogurt was detectable. For this reason, the average firmnesses of the yogurts stored for 1 and $7 \mathrm{~d}$ were used for further discussion (Table 1). Yogurts made in the early season of both years had higher firmness than those made in mid-season and late season. Late-season yogurts had the lowest mean firmness in both years, although it was not significantly lower than that of the mid-season yogurts. The firmness of the set yogurt correlated with the $\mathrm{G}^{\prime}$ of the GDLinduced acid gel made from the same standardized milk $(P<0.01 ; \mathrm{Li}$ et al., 2020). The results suggested that, despite the difference in acidification rate and structural rearrangements (Lucey et al., 1998; Ozcan et al., 2015), the seasonal variation in the $\mathrm{G}^{\prime}$ of a GDL-induced acid gel could largely represent the seasonal variation in the firmness of the set yogurt in this study. Nevertheless, the extent of variation, represented by the CV, was higher for the GDL-induced acid gels (CV 18.5\%) than for the set yogurts (CV 14.7\%). Exopolysaccharide 
produced by the starter culture could contribute to the yogurt structure, diminishing the variation arising from the physiochemical properties of seasonal milk (Sodini et al., 2004).

$G S Y$. The average firmness of the GSY, measured after storage for $1,7,14$, and $28 \mathrm{~d}$, was $363.7,411.6$, 411.5, and $415.1 \mathrm{~N} \cdot \mathrm{s}$, respectively. The firmness increased in first $7 \mathrm{~d}$ of storage and remained stable until $28 \mathrm{~d}$. This increase by about $10 \%$ in the firmness during storage agreed with previous studies (Sodini et al., 2004; Matumoto-Pintro et al., 2011). Of the seasons, the increase in firmness from 1 to $7 \mathrm{~d}$ of storage was greatest and most significant $(P=0.016)$ in the late season. The firmness results during storage indicated that GSY became firmer during the first $7 \mathrm{~d}$ of storage, presumably because the protein network fused and rebodied after the original gel structure had been broken by mixing (Lee and Lucey, 2010). In particular, the increase in firmness during storage was the most pronounced in the late season, when the initial firmness of GSY was the lowest (Table 1).

Consistent over the 2 years, the average firmness of GSY over the storage period followed the same seasonal trend as that of set yogurt, in that the early-season samples had the highest firmness (Table 1). The average firmness of GSY correlated with the firmness of regular set yogurt and the $\mathrm{G}^{\prime}$ of the GDL-induced acid gel $(P<0.01)$. The results suggested that the seasonal variations in the textural properties of a high-protein yogurt such as GSY are similar to, and can be indicated by, those of a regular set yogurt or a GDL-induced acid gel. However, GSY had a greater extent of variation in firmness (CV 22.3\%) than regular set yogurt (CV $14.7 \%)$, suggesting that the influence of seasonality on the yogurt structure was greater in a high-protein system.

Correlation Analysis. Table 2 shows the Pearson correlation coefficients between the firmness of the yogurts and the characteristics of the source milk reported in our previous work ( $\mathrm{Li}$ et al., 2019). The firmness of both set yogurt and GSY had correlations with the milk characteristics similar to the $G^{\prime}$ of the GDL-induced acid gels in our previous study (Li et al., 2020). A higher firmness of both types of yogurt correlated significantly with a higher non-glycosylated $\kappa$-CN content $(P<0.05)$, a lower glycosylated $\kappa-\mathrm{CN}$ content $(P<0.01)$, and a lower glycosylation degree (GD, the percentage of glycosylated $\kappa-\mathrm{CN}$ in the total $\kappa-\mathrm{CN})$ of the $\kappa-\mathrm{CN}(P<0.01$; Table 2$)$ in the milk. Also, the yogurt firmness correlated with the $\alpha$-LA $/ \beta$ LG ratio, the extent of whey protein denaturation, and whey protein-CN micelle association, as did the $\mathrm{G}^{\prime}$ of the GDL-induced acid gels (Li et al., 2020). These correlations suggested that the physicochemical effects of the milk characteristics on GDL-induced acid gelation also probably contributed to the firmness of yogurt. Li et al. (2020) proposed that the seasonal changes in the glycosylation of $\kappa$-CN played the most important role, among the physicochemical properties, in the acid gelation of milk because of their effects on the hydrophobic and electrostatic interactions among the milk proteins (Cases et al., 2003; Oka et al., 2018). To a lesser extent, a higher fraction of heat-induced whey protein- $\kappa-\mathrm{CN}$ complexes present in the serum phase may also have promoted better gelation properties (Anema et al., 2004; Vasbinder et al., 2004; Anema, 2018).

Despite the overall consistency, the correlations between yogurt firmness and milk characteristics, as

Table 1. Fermentation time and firmness of set yogurt and Greek-style yogurt made in years 2016 to 2017 (16/17) and 2017 to 2018 (17/18)

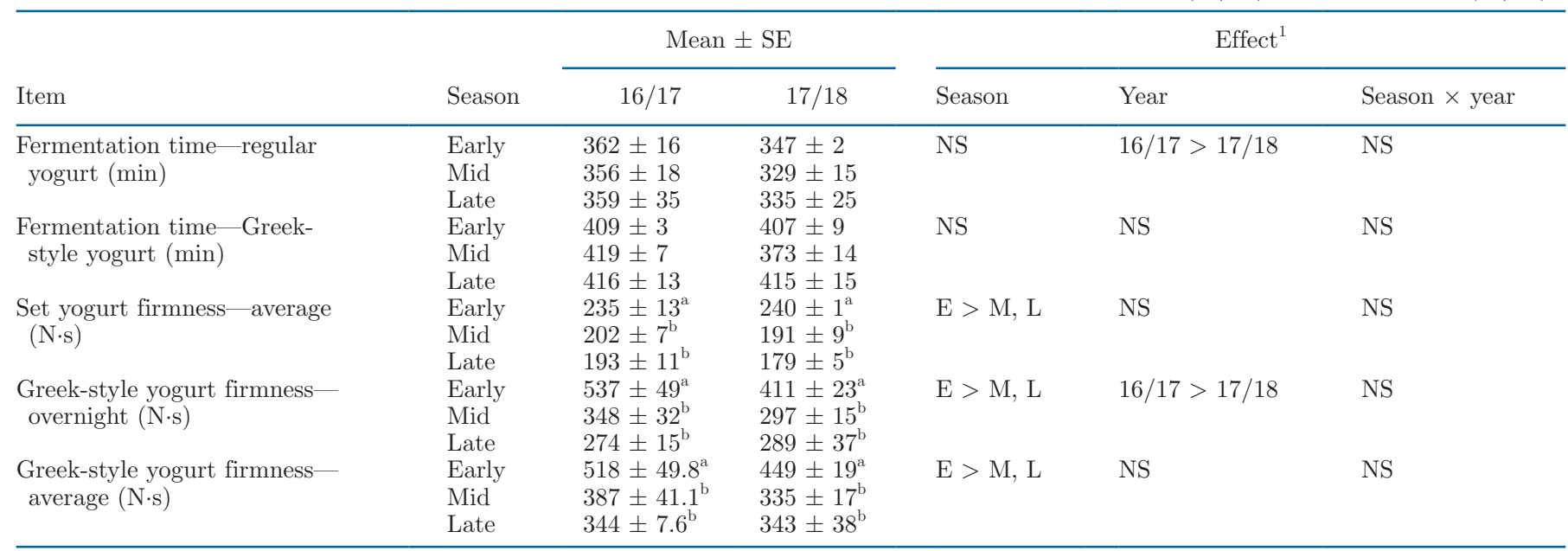

\footnotetext{
${ }^{\mathrm{a}, \mathrm{b}}$ Means of the same parameter within a column with different superscripts differ $(P<0.05,1$-way ANOVA).

${ }^{1}$ Analyzed using 2-way ANOVA. $\mathrm{E}=$ early season; $\mathrm{M}=$ mid-season; $\mathrm{L}=$ late season.
} 
Table 2. Pearson correlation coefficients between yogurt firmness and milk characteristics (Li et al., 2019)

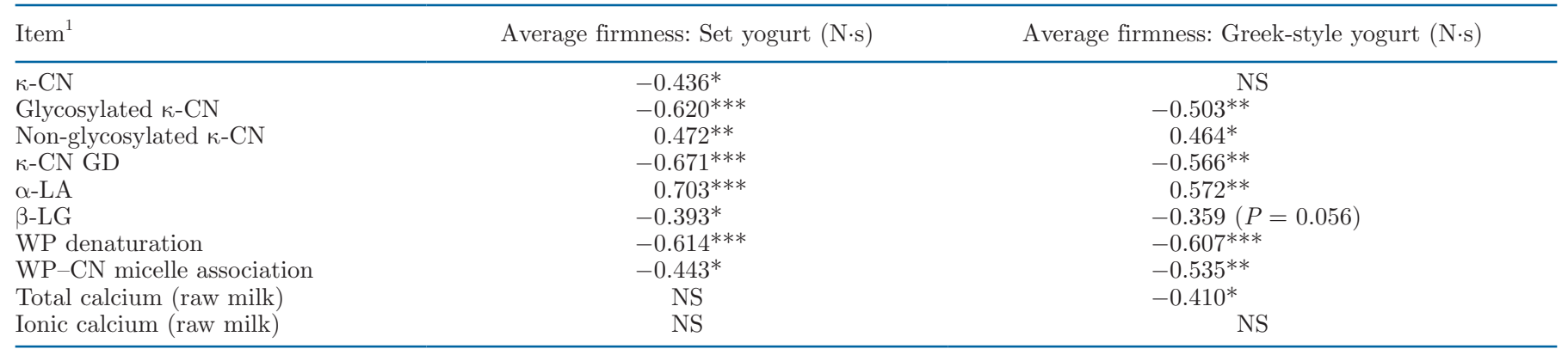

${ }^{1} \mathrm{GD}=$ glycosylation degree; $\mathrm{WP}=$ whey protein.

${ }^{*} P<0.05$; ${ }^{* *} P<0.01 ; * * P<0.001$.

indicated by the correlation coefficients (Table 2), were weaker than those between the $\mathrm{G}^{\prime}$ of GDL-induced acid gels and the milk characteristics (Li et al., 2020). In addition, unlike the $\mathrm{G}^{\prime}$ of GDL-induced acid gels, yogurt firmness did not correlate significantly with the ionic calcium content in the milk. Also, spontaneous syneresis occurred during yogurt fermentation but not during the acidification process using GDL, which may have played a part in affecting the seasonal trends in yogurt firmness (Matumoto-Pintro et al., 2011). The differences in the correlation results between a GDL-induced acid gel and a yogurt highlighted the importance of the GD of $\kappa-\mathrm{CN}$, and potentially the whey protein-CN micelle association, in the acid gelation process during yogurt making. As discussed in Li et al. (2020), factors such as calcium and whey protein composition might not contribute much directly to the acid gelation properties of seasonal milk. Their correlations with the acid gel strength and yogurt firmness probably arose from their interrelations with other parameters, such as the GD of $\kappa-\mathrm{CN}$.

\section{Syneresis and WHC of Yogurts}

Table 3 shows the extent of spontaneous syneresis and the WHC of different types of yogurt. Mid-season set yogurts had the highest levels of spontaneous syneresis and the lowest WHC in both years. Similarly, GSY made in the mid-season had the most pronounced spontaneous syneresis and the lowest WHC, although the variation in spontaneous syneresis was not statistically significant $(P=0.059)$. In contrast, the WHC of stirred yogurt was not affected by seasonal or betweenyear variation.

WHC, under centrifugation, followed the order GSY $>$ stirred yogurt $>$ set yogurt $(P<0.001)$. The level of spontaneous syneresis was lower in GSY (1.94\%) than in regular set yogurt (2.32\%), although the differ-

Table 3. Syneresis and water-holding capacity (WHC) of yogurts made in years 2016 to 2017 (16/17) and 2017 to 2018 (17/18)

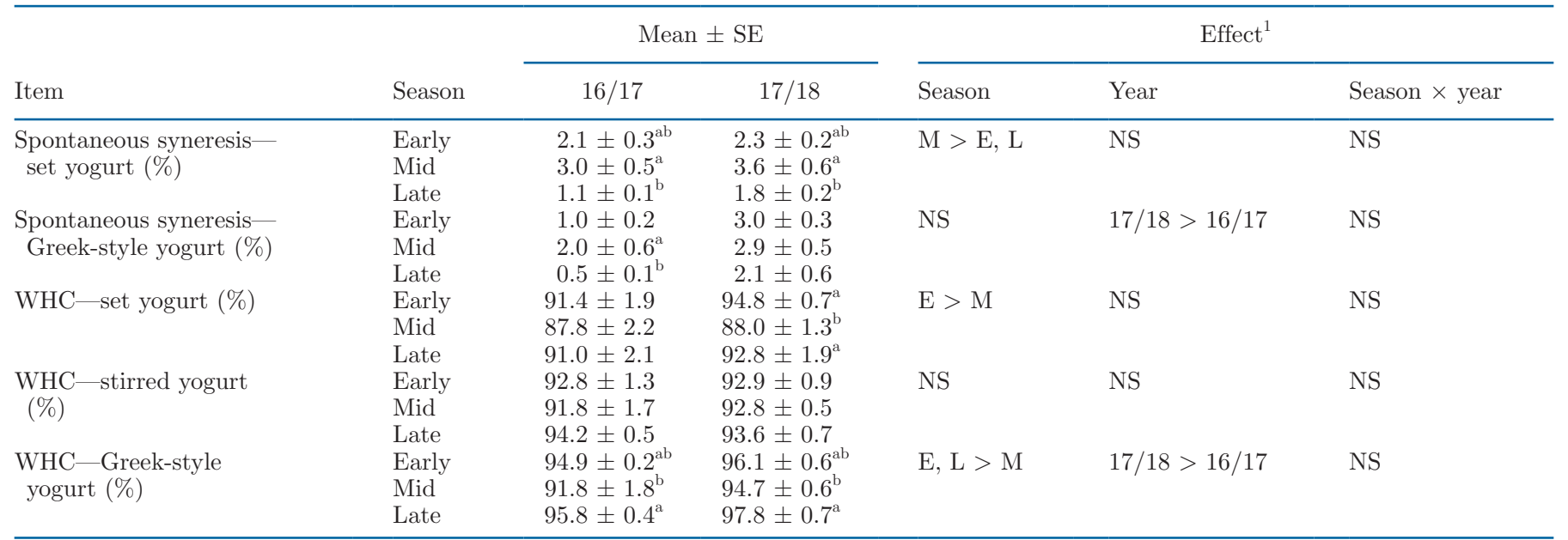

\footnotetext{
${ }^{\mathrm{a}, \mathrm{b}}$ Means of the same parameter within a column with different superscripts differ $(P<0.05,1$-way ANOVA $)$.
}

${ }^{1}$ Analyzed using 2-way ANOVA. E = early season; $\mathrm{M}=$ mid-season; $\mathrm{L}=$ late season. 
Table 4. Viscosity of stirred yogurts made in years 2016 to $2017(16 / 17)$ and 2017 to $2018(17 / 18)$

\begin{tabular}{|c|c|c|c|c|c|c|}
\hline Item $^{1}$ & Season & \multicolumn{2}{|c|}{ Mean $\pm \mathrm{SE}$} & \multicolumn{3}{|c|}{ Effect $^{2}$} \\
\hline$\eta_{0}(\mathrm{~Pa} \cdot \mathrm{s})$ & $\begin{array}{l}\text { Early } \\
\text { Mid } \\
\text { Late }\end{array}$ & $\begin{array}{l}2.76 \pm 0.08 \\
2.55 \pm 0.04 \\
2.73 \pm 0.10\end{array}$ & $\begin{array}{l}3.08 \pm 0.10^{\mathrm{a}} \\
2.52 \pm 0.09^{\mathrm{b}} \\
2.64 \pm 0.04^{\mathrm{b}}\end{array}$ & $\mathrm{E}>\mathrm{M}, \mathrm{L}$ & NS & $*$ \\
\hline$\eta_{\text {median }}(\mathrm{Pa} \cdot \mathrm{s})$ & $\begin{array}{l}\text { Early } \\
\text { Mid } \\
\text { Late }\end{array}$ & $\begin{array}{l}1.08 \pm 0.03^{\mathrm{ab}} \\
0.99 \pm 0.01^{\mathrm{b}} \\
1.18 \pm 0.04^{\mathrm{a}}\end{array}$ & $\begin{array}{l}1.14 \pm 0.05 \\
1.00 \pm 0.03 \\
1.14 \pm 0.03\end{array}$ & $\mathrm{E}, \mathrm{L}>\mathrm{M}$ & NS & NS \\
\hline
\end{tabular}

${ }^{\mathrm{a}-\mathrm{c}}$ Means of the same parameter within a column with different superscripts differ $(P<0.05,1$-way ANOVA).

${ }^{1} \eta_{0}=$ initial viscosity of stirred yogurt; $\eta_{\text {median }}=$ median viscosity of stirred yogurt during 3 min of shearing at $50 \mathrm{~s}^{-1}$.

${ }^{2}$ Analyzed using 2-way ANOVA. $\mathrm{E}=$ early season; $\mathrm{M}=$ mid-season; $\mathrm{L}=$ late season.

*Significant interaction $(P<0.05)$.

ence was not statistically significant $(P=0.142)$. The higher WHC of GSY compared with regular yogurt was presumably due to more effective water binding by the yogurt network because of its higher solids content (Sodini et al., 2004). This was probably the reason for the lack of significance in the WHC of the GSY among the different seasons. The WHC of stirred yogurts also did not vary significantly with the season, which may have been the result of the effects of stirring and storage. For set yogurts, the structural arrangement of the yogurt during fermentation greatly affects their WHC, whereas, for stirred yogurts, the structure of the yogurt gel is broken and is allowed to rearrange during overnight storage. The effect of structural disruption and rebodying probably played a more important role in determining the WHC of the stirred yogurts than did the variation in the structure of the original set yogurt. The slightly higher WHC of the stirred yogurts compared with the set yogurts suggested that the rebodying process effectively entrapped the whey separated both during fermentation and after the stirring process.

\section{Viscosity of Stirred Yogurt}

The viscosities of the stirred yogurts and their resistance to thinning under shear displayed different seasonal trends from the firmnesses of the set yogurts (Figure 3 and Table 4). The initial viscosity $\eta_{0}$ of stirred yogurt was significantly affected by season-year interactions, suggesting different seasonal trends in the 2 years. In 2017 to2018, early-season yogurts had significantly higher $\eta_{0}$ than mid- and late-season yogurts, whereas, in 2016 to 2017, no significant seasonal variation was detectable. Although not statistically significant, the mid-season yogurts in 2016 to 2017 had the lowest mean $\eta_{0}$, of $2.55 \mathrm{~Pa} \cdot \mathrm{s}$, whereas the early- and late-season yogurts had similar viscosities of 2.76 and
$2.73 \mathrm{~Pa} \cdot \mathrm{s}$, respectively. The median viscosity during 3 min of constant shearing $\eta_{\text {median }}$ was lowest in the midseason of both years. The $\eta_{\text {median }} / \eta_{0}$ ratio, as an indicator of the resistance of the viscosity of stirred yogurt to shear-induced thinning, was consistently higher in the late season than in the early and mid-seasons.

Despite being made from set yogurt by stirring, the viscosities of the stirred yogurts did not completely follow the same seasonal trends of the firmnesses of the set yogurts. The results suggested that the viscosity of stirred yogurt was affected by properties other than the firmness of the yogurt before stirring, which varied with the season. The $\eta_{0}$ followed similar seasonal trends to set yogurt firmness, with a strong correlation $(\mathrm{r}=0.64$;

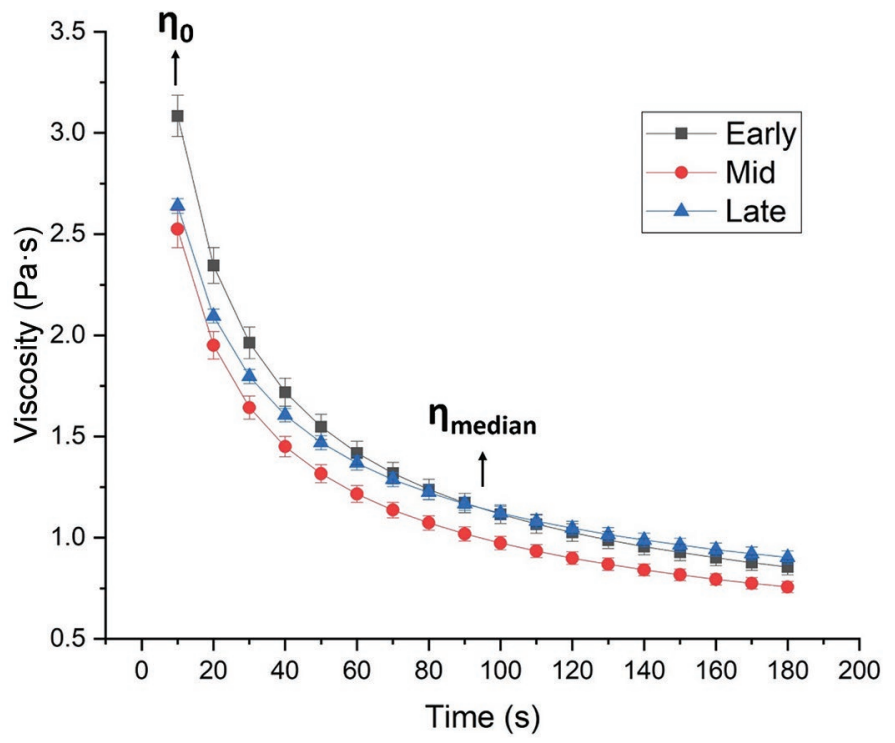

Figure 3. Viscosity reduction of stirred yogurts over time under a constant shear rate $(2017-2018)$. The initial viscosity $\left(\eta_{0}\right)$ and the median viscosity $\left(\eta_{\text {median }}\right)$ are indicated. 
$P<0.001)$. However, the $\eta_{0}$ values of late-season and early-season stirred yogurts made in 2016 to 2017 were comparable, despite the significantly lower set yogurt firmness in the late season (Table 1). In contrast to $\eta_{0}, \eta_{\text {median }}$ did not correlate with the initial firmness of the set yogurts. Stirred yogurts made in the late seasons of both years had $\eta_{\text {median }}$ values similar to those of the stirred yogurts made in the early seasons, and these values were higher than those of the mid-season yogurts. The viscosity test under constant shear can be seen as a continuation of the stirring process. The highest $\eta_{\text {median }} / \eta_{0}$ ratios in the late season indicated that late-season yogurts had the strongest resistance to shear-induced thinning. The results indicated that the inferior acid gelation and yogurt-making properties of late-season milk, as demonstrated in GDL-induced acid gels (Li et al., 2020) and set yogurts, did not affect the structural properties of late-season stirred yogurts in the same way.

The higher viscosity of late-season yogurts relative to their lower initial firmness might be related to the more liquidlike properties of the yogurt gels and the higher WHC compared with those of mid-season yogurts (Table 3). Our study on GDL-induced acid gelation ( $\mathrm{Li}$ et al., 2020) found that the loss tangent at $\mathrm{pH} 4.6$ of acid gels made from regular yogurt milk was highest in the late season (0.31) and lowest in the early season (0.28). The highest loss tangent indicated that late-season milk acid gels and yogurts would have the most liquidlike properties over the seasons. As a result, relatively more shear stress might dissipate through the late-season yogurt structure rather than causing a structural breakdown. As such, the decrease in viscosity under shearing would be lower in yogurts from the late season than in those from the rest of the year. In addition, the WHC of set yogurts correlated with both $\eta_{0}(\mathrm{r}=0.544 ; P<0.01)$ and $\eta_{\text {median }}(\mathrm{r}=0.494 ; P<$ $0.05)$. Lower WHC of the yogurt might result in greater whey separation under stirring and shearing, leading to a more significant reduction in viscosity. This is supported by Matumoto-Pintro et al. (2011), who reported a negative relationship between syneresis and the viscosity of stirred yogurt. As such, the viscosity of stirred yogurts in the mid-season might be reduced to the greatest extent over the seasons because of their highest extent of whey separation.

The $\eta_{\text {median }} / \eta_{0}$ ratio correlated significantly with the GD of $\kappa-\mathrm{CN}(\mathrm{r}=0.808 ; P<0.001)$. Because the glycan groups on glycosylated $\kappa$-CN are hydrophilic, milk with higher GD of $\kappa-\mathrm{CN}$ may have $\mathrm{CN}$ micelles with more hydrophilic surfaces and greater water-binding capacities. Consequently, the higher GD of $\kappa-\mathrm{CN}$ in late-season milk may have contributed to limiting the syneresis of late-season yogurts by increasing the amount of water bound to the proteins. This hypothesis was supported by a moderate but significant negative correlation between the GD of $\kappa-\mathrm{CN}$ and the extent of spontaneous syneresis $(\mathrm{r}=-0.489 ; P<0.01)$. In addition, a higher hydration of the proteins, resulting from a higher $\kappa-\mathrm{CN}$ GD, might also promote the liquidlike properties of acid gels and yogurts made from late-season milk.

\section{CONCLUSIONS}

The fermentation time to reach a certain $\mathrm{pH}$ did not vary with the season for either regular yogurt or GSY. The firmnesses of set yogurt and GSY were highest in the early season, correlating significantly with the $\mathrm{G}^{\prime}$ of GDL-induced acid gels made from the regular yogurt milk base. The results suggest that the seasonal variation in GDL-induced acid gelation could largely represent the seasonal variations in the structural properties of set yogurt and GSY. The physicochemical properties of milk that correlated with the rheological properties of acid gels in our previous study ( $\mathrm{Li}$ et al., 2020 ), primarily the glycosylation of $\kappa-\mathrm{CN}$, might also play an important part in affecting the structure development of yogurt. Mid-season yogurts had the highest level of syneresis and the lowest WHC. The initial viscosity of stirred yogurts displayed similar seasonal trends to the firmness of set yogurts. However, lateseason stirred yogurts showed the strongest resistance to shear-induced thinning. This may have resulted from the unique viscoelastic property of late-season yogurt gels, which were the most liquidlike. The lowest WHC and thus the greatest amount of whey separation of the mid-season yogurts may also have played a role in lowering its viscosity after stirring.

\section{ACKNOWLEDGMENTS}

We gratefully acknowledge Callaghan Innovation (Wellington, New Zealand) for funding the study and Claire Woodhall for proofreading the manuscript. The authors declare no conflict of interest.

\section{REFERENCES}

Anema, S. G. 2018. Effect of whey protein addition and pH on the acid gelation of heated skim milk. Int. Dairy J. 79:5-14. https:// doi.org/10.1016/j.idairyj.2017.11.008.

Anema, S. G., S. K. Lee, E. K. Lowe, and H. Klostermeyer. 2004. Rheological properties of acid gels prepared from heated $\mathrm{pH}$-adjusted skim milk. J. Agric. Food Chem. 52:337-343. https://doi.org/10 $.1021 /$ if034972c.

Auldist, M. J., B. J. Walsh, and N. A. Thomson. 1998. Seasonal and lactational influences on bovine milk composition in New Zealand. J. Dairy Res. 65:401-411. https://doi.org/10.1017/ S0022029998002970.

Bong, D. D., and C. I. Moraru. 2014. Use of micellar casein concentrate for Greek-style yogurt manufacturing: Effects on processing 
and product properties. J. Dairy Sci. 97:1259-1269. https://doi .org/10.3168/jds.2013-7488.

Cases, E., V. Vidal, and J. Cuq. 2003. Effect of k-casein deglycosylation on the acid coagulability of milk. J. Food Sci. 68:2406-2410. https://doi.org/10.1111/j.1365-2621.2003.tb07037.x.

Cheng, L. J., P. T. Clarke, and M. A. Augustin. 2002. Seasonal variation in yogurt properties. Aust. J. Dairy Technol. 57:187.

Desai, N. T., L. Shepard, and M. A. Drake. 2013. Sensory properties and drivers of liking for Greek yogurts. J. Dairy Sci. 96:7454-7466. https://doi.org/10.3168/jds.2013-6973.

Dharmasena, S., A. Okrent, and O. Capps Jr. 2014. Consumer demand for Greek-style yogurt and its implications to the dairy industry in the United States. Proc. Agricultural and Applied Economics Association, Minneapolis, MN. Agricultural and Applied Economics Association, Milwaukee, WI.

Guyomarc'h, F., C. Queguiner, A. J. R. Law, D. S. Horne, and D. G. Dalgleish. 2003. Role of the soluble and micelle-bound heatinduced protein aggregates on network formation in acid skim milk gels. J. Agric. Food Chem. 51:7743-7750. https://doi.org/10.1021/ jf030201x.

Jørgensen, C. E., R. K. Abrahamsen, E.-O. Rukke, T. K. Hoffmann, A.-G. Johansen, and S. B. Skeie. 2019. Processing of high-protein yoghurt-A review. Int. Dairy J. 88:42-59. https://doi.org/10 $.1016 /$ j.idairyj.2018.08.002.

Lee, W. J., and J. A. Lucey. 2010. Formation and physical properties of yogurt. Asian-Australas. J. Anim. Sci. 23:1127-1136. https:// doi.org/10.5713/ajas.2010.r.05.

Li, S., A. Ye, and H. Singh. 2019. Seasonal variations in composition, properties, and heat-induced changes in bovine milk in a seasonal calving system. J. Dairy Sci. 102:7747-7759. https://doi.org/10 $.3168 /$ jds.2019-16685.

Li, S., A. Ye, and H. Singh. 2020. Effect of seasonal variations on the acid gelation of milk. J. Dairy Sci. 103:4965-4974. https://doi.org/ 10.3168 /jds.2019-17603.

Lucey, J. A., and H. Singh. 1997. Formation and physical properties of acid milk gels: A review. Food Res. Int. 30:529-542. https://doi .org/10.1016/S0963-9969(98)00015-5.

Lucey, J. A., M. Tamehana, H. Singh, and P. A. Munro. 1998. A comparison of the formation, rheological properties and microstructure of acid skim milk gels made with a bacterial culture or glucono- $\delta$ lactone. Food Res. Int. 31:147-155. https://doi.org/10.1016/S0963 -9969(98)00075-1.
Lucey, J. A., C. T. Teo, P. A. Munro, and H. Singh. 1997. Rheological properties at small (dynamic) and large (yield) deformations of acid gels made from heated milk. J. Dairy Res. 64:591-600. https: //doi.org/10.1017/S0022029997002380.

Macori, G., and P. D. Cotter. 2018. Novel insights into the microbiology of fermented dairy foods. Curr. Opin. Biotechnol. 49:172-178. https://doi.org/10.1016/j.copbio.2017.09.002.

Matumoto-Pintro, P. T., L. Rabiey, G. Robitaille, and M. Britten. 2011. Use of modified whey protein in yoghurt formulations. Int. Dairy J. 21:21-26. https://doi.org/10.1016/j.idairyj.2010.07.003.

Nsabimana, C., B. O. Jiang, and R. Kossah. 2005. Manufacturing, properties and shelf life of labneh: A review. Int. J. Dairy Technol. 58:129-137. https://doi.org/10.1111/j.1471-0307.2005.00205.x.

Oka, D., W. Ono, S. Ohara, T. Noguchi, and K. Takano. 2018. Effect of heat-induced $\kappa$-casein dissociation on acid coagulation of milk. J. Dairy Res. 85:104-109. https://doi.org/10.1017/ S002202991700084X

Ozcan, T., D. S. Horne, and J. A. Lucey. 2015. Yogurt made from milk heated at different $\mathrm{pH}$ values. J. Dairy Sci. 98:6749-6758. https:// doi.org/10.3168/jds.2015-9643.

Sodini, I., F. Remeuf, S. Haddad, and G. Corrieu. 2004. The relative effect of milk base, starter, and process on yogurt texture: A review. Crit. Rev. Food Sci. Nutr. 44:113-137. https://doi.org/10 $.1080 / 10408690490424793$.

Uduwerella, G., J. Chandrapala, and T. Vasiljevic. 2017. Preconcentration of yoghurt base by ultrafiltration for reduction in acid whey generation during Greek yoghurt manufacturing. Int. J. Dairy Technol. https://doi.org/10.1111/1471-0307.12393.

Vasbinder, A. J., F. van de Velde, and C. G. de Kruif. 2004. Gelation of casein-whey protein mixtures. J. Dairy Sci. 87:1167-1176. https: //doi.org/10.3168/jds.S0022-0302(04)73265-8.

Wood, F. W. 1968. Psychophysical studies on the consistency of liquid foods. Pages 40-49 in Rheology and Texture of Foodstuffs. SCI Monograph 27. Society of Chemical Industry, London, UK.

\section{ORCIDS}

Siqi Li ㄴ) https://orcid.org/0000-0003-4971-9705

Aiqian Ye @ https://orcid.org/0000-0003-1048-8858

Harjinder Singh @ https://orcid.org/0000-0002-8807-3241 